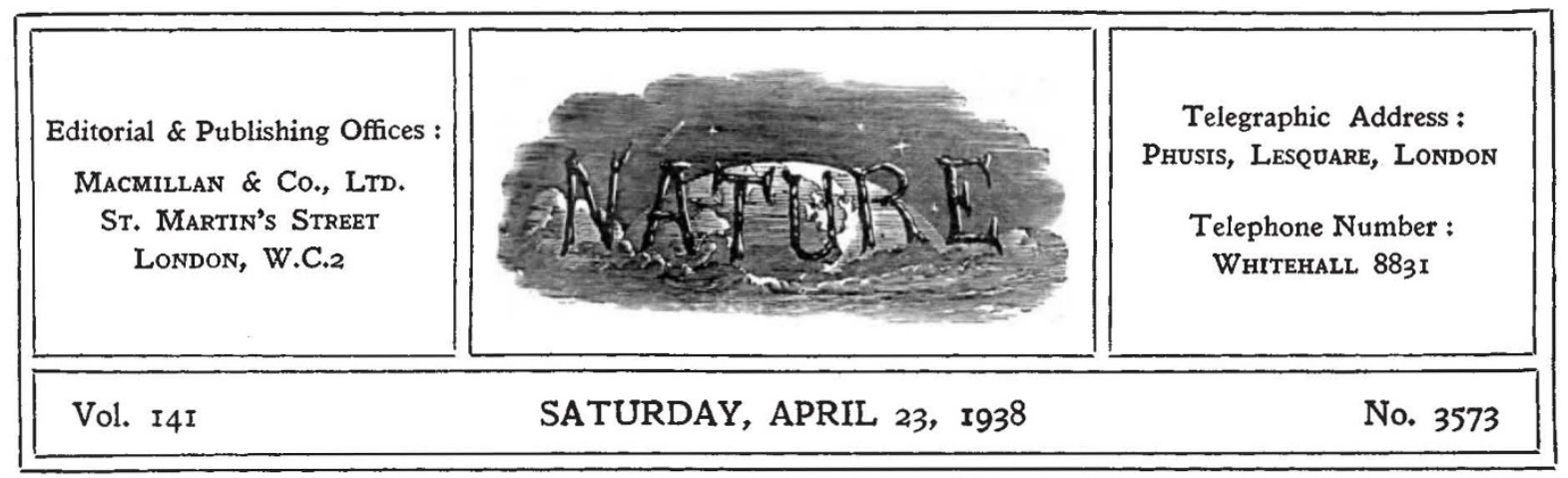

\title{
Medical Inventions and Discoveries
}

$\mathrm{T}$ HE report of the Medical Research Council for the year 1936-37 recently issued* refers to the present unsatisfactory position in Great Britain of the medical treatment known as chemotherapy, which consists in the administration of chemical compounds synthesized in the laboratory and found to have specific actions on the infective organisms causing particular diseases in man and animals. The discovery and production of chemical compounds of value in this way have, the report states, "depended almost entirely on German science and industry, and still so depend", although the subject has special significance for the British Empire with its immense responsibility in tropical countries. Malaria, for example, still holds the premier place as a cause of premature death and inefficiency in the Empire, and it is estimated that in India alone at least $100,000,000$ persons suffer from the disease each year, with a direct financial loss variously estimated at from $£ 23,000,000$ to $£ 50,000,000$ per annum, the indirect losses being still greater. The report then continues as follows :

"Were the matter only one of prestige, the situation would be serious enough, but the financia] aspect is also of much importance. Foreign firms have built up large organizations and have spent large sums of money to advance this aspect of therapeutics. They naturally, therefore, expect to derive substantial profit from any practical discoveries. Not only do they take out comprehensive patents to cover these chemical agents, but they do not as a rule grant licences for manufacture in this country; in case of war, therefore, the British Empire might be deprived of essential drugs, as in the case of salvarsan compounds in 1914."

* Committee of the Privy Council for Medical Research. Report of the Medical Research Council for the Year 1936-7. (Cmd. 5671.) Pp. 195+xiv. (London: H.M. Stationery Office, 1938.) 3s. net.
The success of Germany in the field of research in chemotherapy has been dependent on a system in which the investigations have been made chiefly in large research establishments maintained by manufacturing firms which have employed hundreds of chemists and have persevered for years before achieving results capable of commercial development. In Great Britain, manufacturing chemists, it is stated in the report, "have not appeared willing to use their resources in this manner", the main interests of the larger firms having been in other directions, while the smaller firms have been either unable or unwilling to undertake research of this kind. The report continues, "in these circumstances, the only possibility of securing that this country took its proper part in the matter, in relation to its imperial responsibilities, was a national scheme supported from public funds." A commencement is therefore being made with such a national scheme supported from public funds, for a sum of $£ 30,000$ provided by Parliament has been allocated by the Council "for research in chemotherapy, in the first instance in respect of the cost of the new buildings required", and it is stated that such a scheme would attempt to follow with Government support the general line of action of a great commercial organization taking up this subject of research. Presumably the scheme would be under the control of the Council and, so far as is indicated in the report, would operate without the direct co-operation of industry.

It is not clear on what grounds the Council bases its opinion that in existing circumstances the only possibility of securing that Great Britain may take its proper part in the matter is such a national scheme supported from public funds. Presumably 
one of the grounds is the inference that because, as alleged, manufacturing chemists in this country "have not appeared willing to use their resources [for research] in this manner", they are now and will continue to be unwilling. There is, however, no sub. stantial evidence in the report that the manufacturing chemists either have been or are at present unwilling to use their resources in this manner. On the other hand, evidence from other sources supports the opposite opinion, at least in so far as concerns certain manufacturing chemists, for in 1931 a scheme for the compulsory dedication of patents to the public and their administration by a State department was submitted to the Departmental Committee on the Patents and Designs Acts by a Joint Chemical Committee representing several chemical institutions, and it was stated that the scheme might be regarded as the expression of opinions held in common by most of those concerned in the practice of chemistry in Great Britain. It is clear, therefore, that in 1931 these manufacturing chemists were willing to co-operate, and there is no reason to think that they are less willing to do so to-day; indeed, there is reason to believe from recent statements in the Press that they are not only willing but even anxious to co-operate.

There was, however, opposition to the scheme put forward by the Joint Chemical Committee, and the Departmental Committee reported that although no question considered by it had attracted more attention or been the subject of more conflicting evidence, the definite conclusion had been reached that no sufficient case had been made out for any compulsory dedication.

In view of this definite conclusion and of the lack of evidence to support the circumstances on which the Council bases its opinion as to the only possible scheme, it may be pointed out that there are now in operation in other countries at least two quite different schemes in each of which science and industry are co-operating with one another.

The first is a scheme for the voluntary dedication of medical patents, which is in existence both in Canada and in the United States. In Canada, the ownership of the insulin patent was placed in the hands of the University of Toronto, and has since been efficiently administered by that authority, and in many foundations in the United States there have been drawn up rules regulating the conditions under which patents may be dedicated to them. In the United States, during the past few years, there has been a growing recognition on the part of university administrators that only through the proper use of the patent system can the public benefit of certain of the inventions which are made in their laboratories be ensured and the undesirable aspects of patent exploitation avoided. It is felt in that country that mere publication of a scientific paper disclosing an invention does not prevent patenting of the invention by some individual with a hazy fragmentary prior record along the same general lines. The inventions may easily get into unscrupulous hands and the public may be exploited through this unforeseen result of a programme of institutional research. There is, however, no substantial evidence that opinion among medical men and manufacturing chemists in Great Britain would favour the adoption of a scheme for the voluntary dedication of medical. patents.

The second scheme in which science and industry are co-operating is that which has already been established in Germany with such satisfactory results to that country and such unsatisfactory and even dangerous results to our own country. According to the report of the Medical Research Council, the discovery and production of compounds of value in chemotherapy have "depended almost entirely on German science and industry, and still so depend", and in the opinion of the Council the difference between the practice in Germany and the practice in Great Britain is that whereas in Ger. many large research establishments maintained by manufacturing firms have employed hundreds of chemists and have persevered for years before achieving results capable of commercial development, British manufacturing chemists have not appeared willing to use their resources in this way. There is, however, another important difference, produced by the fact that medical men in Great Britain have not readily given their co-operation to test a therapeutic agent that is the subject of proprietary rights. In the evidence submitted by the Medical Research Council to the Departmental Committee on the Patents and Designs Acts it is stated that :

"There is not there [in Germany] the same feeling against the taking of patents by medical men, and many physicians attached to public hospitals and University Clinics are ready to investigate new remedies on behalf of a commercial patentee, on a footing similar to that of the consulting chemist."

It should be remembered also that manufacturing firms are placed under other serious 
limitations in respect of medical patents by the law of this country. For example, by Section 38A of the Patents and Designs Acts, 1907-1932, a medical patent must be of defined limited scope and "the Comptroller shall, unless he sees good reason to the contrary, grant to any person applying for the same, a licence" to use the invention; and again, by the Therapeutic Substances Act, 1925, a scheduled therapeutic substance may be manufactured only under licence, and a Joint Advisory Committee consisting of representatives of the Ministry of Health and medical and scientific bodies fixes the standards of purity, strength, etc.

In view of these facts, it is not clear either that the circumstances alleged by the Medical Research Council have a sufficiently firm foundation on which to base its opinion as to the only possible scheme, or that the scheme proposed is the one most likely to attain the desired end. Is it to be seriously contended that a scheme controlled solely by British science without the aid of British industry will be able to displace German science and industry, working in harmony, from the strong position in chemotherapy which they already hold in Great Britain? Would it not be better in making a forward step to try once again to follow the path which has led Germany to success through willing co-operation between science and industry, than to embark on an uncharted course controlled solely by science without the willing co-operation of industry? The immense responsibilities of the British Empire in tropical countries and the dangerous position of Great Britain in the event of war seem to make it imperative that, before any untried plan is proceeded with, every possible effort should be made by all the parties concernedscientific men, medical men, and manufacturing chemists-to evolve a scheme of the kind which has already brought success to Germany, whereby the willing co-operation of science and industry will rectify our unsatisfactory peace-time position by rendering the country independent of foreign supplies of chemotherapeutic drugs.

\section{Knowledge and World Progress}

\section{World Brain}

By H. G. Wells. Pp. xvi +130 . (London : Methuen and Co., Ltd., 1938.) 3s. 6d. net.

$\mathrm{T}$ HIS, the latest of Mr. Wells's books, may well be the latest-but-one before this review appears, so swift is the rush of his ideas, so urgent the message which he has for a civilization clatter ing blindly towards chaos. Here, as in so much of his work, we have yet another contribution towards that orderly world-scheme so dear to the heart of the ever-young, wise and keenly interested recruit to the ranks of the septuagenarians. The essays collected in the hundred and thirty pages of this slight and engrossing volume comprise a Friday evening discourse delivered at the Royal Institution, a lecture given in America, a contribution to the Encyclopédie Française, the presidential address to Section $\mathrm{L}$ of the British Association on "The Informative Content of Education" and a series of appendices evoked by the comments of those sensitive souls ruffled by the more provocative parts of his addresses.

For provocative Mr. Wells is-and long may he remain so! To some he may, now and then, seem to lay more stress on the material than the spiritual factors that have contributed to the making of history. As when he tells us that "in the middlenineteenth century all Europe thought that the United States must break up into a lawless confusion. The railway, the printing press, saved that." That is a literal truth. But the mind of Abraham Lincoln, a man as great as some of the strutting leaders of a later age are small, was surely the determining factor in the preservation of the Union.

These divagations, however, are but incidental, and in most of these addresses Mr. Wells seldom wanders far from his main theme-the gathering, indexing, digesting and clarifying of the sum total of present knowledge into an ever-changing, evergrowing World Encyclopædia, which shall not only serve the needs of the specialized student, but also shall give to the citizen of the nation of to-day something of the factual and critical knowledge necessary to make easy his progress towards citizenship of that world-federation to which he is, paradoxically enough, stumbling through a phase of intensified nationalism.

There never was a time in the history of mankind when it was more necessary that this oraered knowledge should be at the beck and call of all of us-when the elements of success are in the hands of those who can combine an emotional drive towards the light with an intellectual appreciation 